American Journal of Applied Sciences 6 (2): 361-367, 2009

ISSN 1546-9239

(C) 2009 Science Publications

\title{
Detection of DNA Hypomethylation Mediated Floral Induction in Longan and Spinach Using the HAT-RAPD Technique
}

\author{
${ }^{1}$ S. Anuntalabhochai, ${ }^{2}$ R. Chundet, ${ }^{1}$ N. Buapong and ${ }^{3}$ R.W. Cutler \\ ${ }^{1}$ Department of Biology, Faculty of Science, Chiang Mai University, Chiang Mai, Thailand \\ ${ }^{2}$ Department of Biology, Faculty of Science, Maejo University, Chiang Mai, Thailand \\ ${ }^{3}$ Bard College, Annandale-on-Hudson, New York, USA. 12504
}

\begin{abstract}
In this study, the HAT-RAPD technique was used to detect DNA methylation in the four plant species, rice (Oryza sativa), petunia (Petunia hybrida), spinach (Spinacea oleracea L.) and longan (Dimocarpus longan Lour.), which were treated using 5-azacytidine, potassium chlorate $\left(\mathrm{KClO}_{3}\right)$ and a low temperature induction. Rice and petunia were chosen to be induced because in these species it is known that 5-azacytidine is able to induce hypomethylation in their genomes leading to morphological changes, in particular floral induction, in the developing plants. Using the HAT-RAPD technique, DNA methylation was detected using the restriction enzymes HpaII and MspI in rice and petunia (as expected) and in spinach, but was found to be absent in longan, which suggests that floral induction in longan is undetectable in longan.
\end{abstract}

Key words: Longan, spinach, hypomethylation, vernalization, HAT-RAPD, temperature dependence

\section{INTRODUCTION}

Many plants in temperate zones require a low temperature stress (vernalization) to induce flowering and fruit production. In some plants such as Arabidopsis and Cichorium intybus the vernalization response has been linked to changes in DNA methylation $^{[1,2]}$, while the seedlings of other plants like Oryzia sativa are regularly treated with 5-azacytidine which results in dwarfism and a high tillering number due to hypomethylation of the cytosine nucleotide ${ }^{[3,4]}$. Alternatively, treatment of petunia seedlings with 5-azacytidine results in inhibition of shoot bud induction which is also mediated, at least partly, by the alteration of cytosine DNA methylation patterns ${ }^{[5]}$. The parallels between the inheritance of the vernalization signal and DNA methylation patterns indicates that one common biochemical signaling system for vernalization is DNA methylation dependent. To investigate the mechanism of vernalization in other tropical plants, particularly Longan (Dimocarpus longan Lour.) and spinach (Spinacea oleracea L.) the demethylation agent 5-azacytidine and $\mathrm{KClO}_{3}$ application, in addition to natural temperature stress, was used to test for the presence of altered DNA methylation patterns.

The process of DNA methylation is a common modification of cytosine nucleotides seen in many eukaryotic organisms and in plant DNA, up to $30 \%$ of all the cytosine residues that exist as $\mathrm{CpG}$ or $\mathrm{CpNpG}$ sequence can have detectable levels of methylation ${ }^{[6]}$. This modification directly affects DNA structure and hence can interrupt the interaction between a DNA template and RNA polymerase increasing the possibility of aborted transcription ${ }^{[3]}$. Although DNA methylation seems to be a widespread mechanism present in eukaryotic organisms, the level and effect of DNA methylation can vary depending on species and developmental status. In plants, the alteration of methylation patterns is of particular interest since it can lead to morphological changes which can affect flowering patterns and overall plant development.

Due to the low temperature requirement for flower induction of many tropical fruits, the availability of these fruits is limited to narrow seasons which exactly match the required environmental conditions. One remarkable advancement in tropic fruit production is the recent determination that potassium chlorate can induce out of season flowering in Longan ${ }^{[7]}$. This has lead to the widespread and year-round availability of Longan both domestically and as a growing product for export ${ }^{[8]}$. By understanding the mechanism of action inducing this out of season fruit production, insight into other tropical fruits may lead to further advances making other fruits such as Lychee or Longong similarly available. Recently, molecular markers linked to the temperature independence for fruit production

Corresponding Author: R.W. Cutler, Bard College, Annandale-on-Hudson, NY 12504 USA Tel: 66 (0) 848-048-767 Fax: 66 (0) 053-892-259 
phenotype in both Lychee ${ }^{[9]}$ and Longan ${ }^{[10]}$ have been reported. In spinach, potassium chlorate and 5-azacytidine-treated spinach both develop an early flowering phenotype ${ }^{[11]}$, indicating that potassium chlorate might also play a similar role to 5$\operatorname{azacytidine}^{[12]}$.

In this study, we investigated DNA methylation patterns in longan and spinach which were induced by 5-azacytidine, potassium chlorate $\left(\mathrm{KClO}_{3}\right)$ and low temperatures, using the HAT-RAPD methodology (High Annealing Temperature-Random Amplified Polymorphic DNA ${ }^{[13]}$. This method is based on the random amplified polymorphic DNA (RAPD) technique combined with the application of isochizomers (HpaII and MspI) that differ in their sensitivity to methylation of their recognition sequences. In particular, both enzymes recognize the nucleotide sequence 5'-CCGG-3', where HpaII is inactive if one or both cytosines are methylated otherwise HpaII cleaves the recognition site, whereas $M s p I$ is inactive if the outer cytosine is methylated but cleaves if the inner cytosine is methylated ${ }^{[14]}$. If a site interior to an RAPD amplified region is cleaved by a restriction enzyme then the DNA cannot be amplified and the corresponding band is absent. By characterizing altered amplification products due to the demethylation effects of 5-azacytidine upon the genome, the presence or absence of methylation linked to phenotypic alterations in longan and spinach can be studied using the RAPD technique.

\section{MATERIALS AND METHODS}

Plant materials: For each of the four species under study, samples were obtained and processed at the University of Chiang Mai in Chiang Mai Thailand. The 10 year old longan (Dimocarpus longan Lour. Var. Daw) trees were kindly provided by a private local orchard in the Hangdong district of the Chiang Mai province. The spinach (Spinacea oleracea L.) F1 hybrid var HI-UP 6901 seeds were obtained commercially (Know-you seeds Co., Ltd). Samples of Thai jasmine Rice (Oryza sativa indica cv. KDML 105) were provided by the Sun Pah Tong Rice Research Center in the Chiang Mai province. The petunia (Petunia hybrida var Border Gem) seeds were obtained from Arthur Yates and Co Ltd., Australia.

Tissue culture conditions: The Oryza sativa cv. KDML105 seeds were initially prepared by surface sterilizing the decoated seeds in a $70 \%$ ethanol and $10 \%$ clorox solution, followed by a sterile distilled water rinse. Seedlings were grown in a modified MS medium supplemented with 0 and $25 \mu \mathrm{M}$ 5-azacytidine ${ }^{[4]}$. During the initial seed preparation, the $\mathrm{pH}$ was adjusted to 5.8 prior to autoclaving at $121^{\circ} \mathrm{C}$ for $20 \mathrm{~min}$. The cultures were then incubated at $25^{\circ} \mathrm{C}$ in total darkness for 5 days followed by a $16 \mathrm{hr}$ light/day incubation condition, using fluorescent tubes (OSRAM 31) as a source of photosynthetic photon flux density (PPFD) at $43 \mu \mathrm{moL} \mathrm{m} \mathrm{sec}^{-1}$ for a period of 2 weeks. The seedlings were then transferred to a standard sand pot and bathed with water and chemical fertilizer $(\mathrm{N}: \mathrm{P}: \mathrm{K}=15: 15: 15)$ was applied once a week. Phenotypic alterations in height and tiller number were recorded at full maturation (flowering stage).

Petunia hybrida seeds were surface sterilized using the same methods as with the rice. Seedlings were cultured in modified MS medium supplemented with 0 , 50 and $100 \mu \mathrm{M} 5$-azacytidine ${ }^{[5]}$ and incubated at $25^{\circ} \mathrm{C}$ under a $16 \mathrm{hr}$ light/day for a period of 2 weeks. Then additional MS liquid medium, supplemented with each concentration of 5-azacytidine, was applied and the seedlings were cultured under identical conditions for an additional 2 weeks. The 4 week old seedlings were then transferred to sand pots. Phenotypic alterations in height, shoots per plant, leaves per plant and days to flowering were recorded.

The spinach (Spinacia oleracea L.) seeds were dipped in $70 \%(\mathrm{v} / \mathrm{v})$ ethanol for $30 \mathrm{~s}$ and then surfacesterilized for $2 \mathrm{~h}$ with a sodium hypochlorite solution (10\% active chlorine) containing a few drops of Tween 20. Then they were rinsed with $3 X$ sterile distilled water and aseptically placed on an agar-solidified medium containing MS medium without plant growth hormone. The seeds (20 seeds/bottle) were incubated at $25+/-2^{\circ} \mathrm{C}$ at light intensity of $40 \mu \mathrm{moL} \mathrm{m}{ }^{-2} \mathrm{sec}^{-1}$ for $14 \mathrm{~h}$ until germination. After the initial growth period (four-leaf stage), seedlings were carefully transferred to grow pots $(7.5 \mathrm{~cm}$ in diameter and $15 \mathrm{~cm}$ in height) with MS media containing $125 \mu \mathrm{M} 5$-azazytidine, $250 \mu \mathrm{M} \mathrm{KClO}_{3}$, or induced with low temperatures $\left(10^{\circ} \mathrm{C}\right)$ for 20 days. The seedlings which were not exposed to a treatment effect were used as a control. Liquid MS medium was refilled in the bottles every 2 weeks. Each experiment was performed with 50 replicates.

Longan (Dimocarpus longan, Lour.) trees of the Daw variety were chosen for $\mathrm{KclO}_{3}$ application to induce out of season floral induction. Each tested tree was treated with $\mathrm{KclO}_{3}$ suspended in water then supplied as a soil drench into cleared soil surface beneath the tree, which was subsequently irrigated. The quantity of $\mathrm{KclO}_{3}$ application was $1 \mathrm{~kg}$ tree ${ }^{-1}$. Five 10 year old mature trees were used for the experiment. 
Genomic DNA isolation: Fresh leaves were collected from each of the plants under study. In each case, approximately $1 \mathrm{~g}$ of leaf tissue was ground in liquid nitrogen and the DNA was extracted using the CTAB method $^{[15]}$. Briefly, to the ground leaf tissue, 400-600 $\mu \mathrm{L}$ of CTAB extraction buffer (100 mM TrisHCL, pH 8.0, 1.4 M NaCl, $20 \mathrm{mM}$ EDTA, 4\%(w/v) CTAB, $1 \%$ Polyvinyl polypyrrolidone (PVPP), $0.1 \% 2$ mercaptoethanol) was added and then incubated at $60^{\circ} \mathrm{C}$ for $1 \mathrm{hr}$. An equal volume of chloroform was added and centrifuged at 13,000 rpm for $5 \mathrm{~min}$. The supernatants were stored and 0.6 vol of ice-cold isopropanol was added and precipitated overnight at $20^{\circ} \mathrm{C}$. The samples were then centrifuged at $13,000 \mathrm{rpm}$ for $10 \mathrm{~min}$ and the supernatant was discarded. The resulting DNA pellet was washed with $70 \%$ ethanol, dried and resuspended in $100 \mu \mathrm{L}$ TE buffer. Further purification of the DNA was done by treating with RNase A $\left(10 \mu \mathrm{g} \mu \mathrm{L}^{-1}, 65^{\circ} \mathrm{C}\right.$ for $\left.30 \mathrm{~min}\right)$. Following this, an equal volume of phenol : chloroform : isoamyl (25:24:1) was added and mixed thoroughly before centrifuging at 13,000 rpm for $5 \mathrm{~min}$. The sample was again precipitated overnight at $-20^{\circ} \mathrm{C}$ following an icecold absolute ethanol wash. The samples were then centrifuged a third time $(13,000 \mathrm{rpm}, 10 \mathrm{~min})$ and the DNA pellets washed with $70 \%$ ethanol prior to drying and resuspending in $50 \mu \mathrm{L}$ TE buffer.

Restriction enzyme digestion: Approximately $50 \mathrm{ng}$ genomic DNA from the control and the 5-azacytidinetreated samples were restricted individually by $20 \mathrm{U}$ methylation-sensitive enzymes ( $H p a I I$ and $M s p I$ ) with a total volume of $50 \mu \mathrm{L}$, using the buffers supplied by the manufacturer (New England Biolabs). The reactions were incubated overnight at $37^{\circ} \mathrm{C}$. The completed digestion was then analyzed using agarose gel electrophoresis.

High annealing temperature random amplified polymorphic DNA (HAT-RAPD) technique: The PCR reactions were carried out with each respective sample using the arbitrary primers OPW09 (GTGACCGAGT), OPL04 (GACTGCACAC) and OPL14 (GTGACAGGCT) (Operon Technologies Alameda, California, USA). For the Longan samples an additional three random primers OPC09 (CTCACCGTCC), OPH06 (ACGCATCGCA) and OPL15 (AAGAGAGGGG) were used to further verify the methylation results. An aliquot of genomic DNA (20-25 ng) was added to the reaction mixture $(30 \mu \mathrm{L})$ containing 1xbuffer (Promega, U.S.A.), $2 \mathrm{mM} \mathrm{MgCl}$, $200 \mu \mathrm{M}$ dNTP, $100 \mathrm{ng}$ primer and $0.5 \mathrm{U}$ Taq DNA polymerase (Promega, U.S.A.). The cycling conditions were $94^{\circ} \mathrm{C}$ for $2 \mathrm{~min}$ providing an initial denaturation followed by 30 cycles of $94^{\circ} \mathrm{C}$ for $30 \mathrm{sec}, 46^{\circ} \mathrm{C}$ for $30 \mathrm{sec}, 72^{\circ} \mathrm{C}$ for $45 \mathrm{sec}$ and a final extension at $72^{\circ} \mathrm{C}$ for $5 \mathrm{~min}$. The reaction products were separated by electrophoresis on a $1.4 \%$ agarose gel and visualized by UV light after ethidium bromide staining.

\section{RESULTS AND DISCUSSION}

To test for the presence of DNA methylation dependent floral induction in the four plant species rice, petunia, longan and spinach, multiple treatment effects were tested in combination with a characterization of the corresponding phenotypic changes in each species. Since rice and petunia are known to exhibit methylation dependent phenotypic changes ${ }^{[16]}$ these two species were treated with 5-azacytidine as positive controls for the RAPD methodology. In spinach the three known inducers of modified floral induction (5-azacytidine, $\mathrm{KCLO}_{3}$ and low temperatures) were tested for the presence of DNA methylation in addition to the characterization of phenotypic differences of each treatment effect. In longan, plants treated with potassium chlorate to induce floral induction were tested for the presence of DNA methylation. In each case, the phenotypic changes were statistically quantified in addition to testing for the presence of DNA methylation using RAPD detection.

Phenotypic effect of inducers: In rice, neither tested traits, the total height and number of stalks per plant, showed statistically significant differences between the plants treated with $25 \mu \mathrm{M}$ of 5 -azacytidine and the control (Table 1). Although the differences were not significant, the total height of the treated plants were on average $16 \%$ smaller than the controls with an increased number of stalks per plant which is consistent with the 5-azacytidine results on rice reported by Cherdshewasart ${ }^{[4]}$.

Table 1: The effect of 5-azacytidine on growth and number of stalks per seed in Oryzia sativa versus control. The mean plus or minus the standard deviation is given for each measurement. No statistically significant differences were found between the treatment and control

\begin{tabular}{|c|c|c|}
\hline & \multicolumn{2}{|l|}{ Treatments } \\
\hline & 5-azacytidine $(25 \mu \mathrm{M})$ & Control \\
\hline Height $(\mathrm{cm})$ & $22.83 \pm 7.38$ & $27.14 \pm 9.45$ \\
\hline Stalks (stalks/seed) & $2.860 \pm 2.19$ & $2.080 \pm 1.51$ \\
\hline Sample size (plants) & 12 & 7 \\
\hline
\end{tabular}

In petunia, the two treatments with 5-azacytidine $(50$ and $100 \mu \mathrm{M})$ showed several statistically significant 
differences from the control including the height of plants which was increased in size as well as the number of days to flowering which was reduced versus the control (Table 2). At 12 weeks, the differences in development of the treated plants versus control plants were quite pronounced (Fig. 1).

For spinach and longan some evidence that the modified treatment effects actually effect the plants was required so that a negative methylation result would not just be due to a non-functioning treatment effect. Since the methylation dependence of vernalization in spinach had not been previously studied, three treatment effects (5-azacytidine, $\mathrm{KclO}_{3}$ and low temperature) were tested for phenotypic changes to indicate there may be a possible methylation dependent effect. The phenotypic traits of height at flowering, number of vegetative leaves per plant, fresh weight and number of days to flowering were chosen to be tested. Of these only the number of days before flowering had a significant difference between the treatments and control. For all three treatment effects, the number of days before flowering was reduced by more than a week (Table 3). Likewise in longan, the treatment of adult trees with potassium chlorate, as is now done commercially, provided floral induction in the tested trees versus the control which did not flower. So for both longan and spinach, detectable phenotypic effects on flower induction were observed and these effects were further tested for the presence of a corresponding methylation effect in the treated plants not present in the control.

Investigation of DNA methylation by HAT-RAPD: To test for a difference in methylation between the treated samples for each species and control, the two enzymes HpaII and MspI were chosen to digest the genomic DNA of each sample. The DNA resulting from this methylation dependent digestion was then amplified using PCR which allowed an inspection of banding patterns for each arbitrary primer to be compared. An agarose gel was run for each arbitrary primer/enzyme combination and differences noted. Rice and petunia were chosen as positive controls since they are known to exhibit changes in methylation for the floral induction treatments examined here.

In rice using the three primers OPW09, OPL04 and OPL14 and digestion with the two enzymes, a total of eleven distinct differences in band pattern were found between untreated samples and control with concurrent digestion by enzyme with zero differences as expected when no additional DNA enzyme digestion was performed (Fig. 2). Using the same methodology, in Petunia with the two primers OPW09 and OPL04 and digesting the genomic DNA with the same two enzymes as in rice, a total of eleven polymorphic bands were found. Since the HAT-RAPD technique was able

\begin{tabular}{|c|c|c|c|}
\hline & $\begin{array}{l}\text { Treatments } \\
5 \text {-azacytidine } \\
(50 \mu \mathrm{M})\end{array}$ & $\begin{array}{l}\text { 5-azacytidine } \\
(100 \mu \mathrm{M})\end{array}$ & Control \\
\hline Height $(\mathrm{cm})$ & $28.40 \pm 7.74$ & $38.38 \pm 12.31$ & $22.42 \pm 8.24$ \\
\hline $\begin{array}{l}\text { Number of branches } \\
\text { per plant }\end{array}$ & $2.710 \pm 1.49$ & $2.540 \pm 1.510$ & $3.250 \pm 1.82$ \\
\hline Number of leaves per plant & $14.08 \pm 4.38$ & $15.46 \pm 7.290$ & $14.33 \pm 3.39$ \\
\hline $\begin{array}{l}\text { Number of days to } \\
\text { flowering (days) }\end{array}$ & $85.46 \pm 1.86$ & $84.38 \pm 1.710$ & $88.67 \pm 3.31$ \\
\hline Sample size (plants) & 24 & 13 & 12 \\
\hline
\end{tabular}

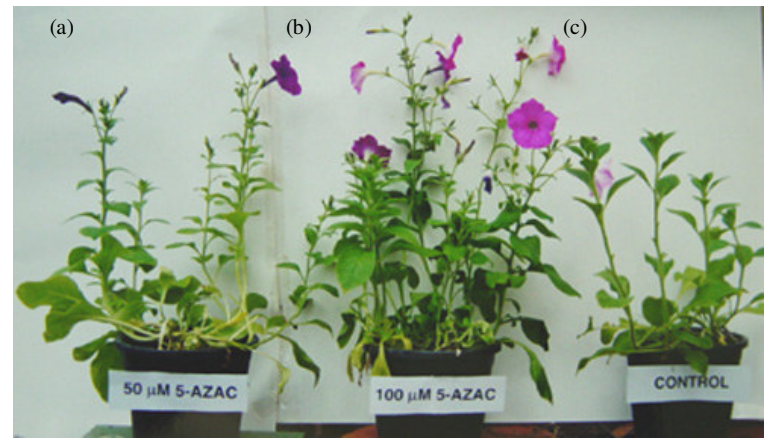

Fig. 1: Petunia plants at 12 weeks of age after treatment with (a): $50 \mu \mathrm{M}$ 5-azacytidine, (b): $100 \mu \mathrm{M}$ 5azacytidine and (c): The control

Table 3: The effect of 5-azacytidine, $\mathrm{KCLO}_{3}$ and low temperature (at $10^{\circ} \mathrm{C}$ for 20 days) on the growth and development of spinach floral induction. All three treatment effects produced significantly reduced times to flowering

\begin{tabular}{|c|c|c|c|c|}
\hline & \multicolumn{4}{|l|}{ Treatments } \\
\hline & 5-azacytidine $(125 \mu \mathrm{M})$ & $\mathrm{KClO}_{3}(250 \mu \mathrm{M})$ & Low temp treatment $10^{\circ} \mathrm{C}, 20$ days & Control \\
\hline Height after flowering (cm) & $5.280 \pm 2.67$ & $5.570 \pm 3.68$ & $4.050 \pm 3.08$ & $4.310 \pm 2.14$ \\
\hline \# of vegetative leaves per plant & $5.080 \pm 1.68$ & $5.170 \pm 1.50$ & $4.550 \pm 1.15$ & $4.560 \pm 0.73$ \\
\hline Fresh weight $(\mathrm{g})$ & $0.520 \pm 0.44$ & $0.490 \pm 0.32$ & $0.340 \pm 0.20$ & $0.360 \pm 0.15$ \\
\hline \# of days before flowering (days) & $36.50 \pm 6.61$ & $36.11 \pm 6.86$ & $37.00 \pm 5.66$ & $45.67 \pm 6.02$ \\
\hline Sample size (plants) & 12 & 18 & 20 & 9 \\
\hline
\end{tabular}


Am. J. Applied Sci., 6 (2): 361-367, 2009

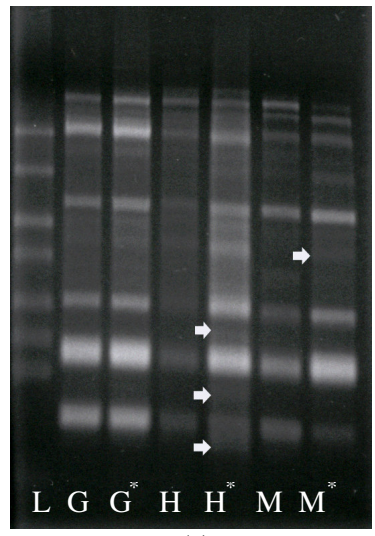

(a)

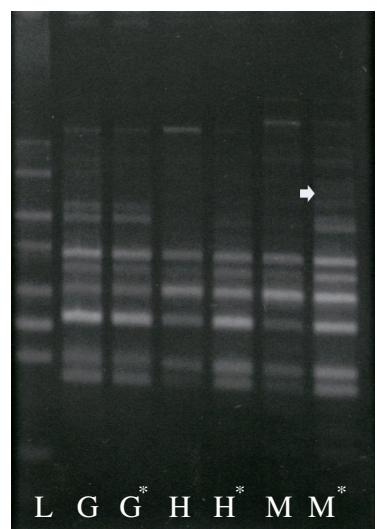

(b)

Fig. 2: Comparison of HAT-RAPD bands in rice between treated groups and control at the age of 20 weeks. Lanes are marked depending on what enzyme was used to digest the genomic DNA where lanes $(\mathrm{G})$ were undigested, $(\mathrm{H})$ digested with HpaII and (M) digested with MspI. Lanes marked with a star (*) were treated with 5azacytidine and the standard ladder is labeled (L). Arrows indicate the polymorphic bands. The arbitrary primer OPW09 was used in frame (a) and OPL04 in (b). Note the arrows which indicate the polymorphic band positions for each agarose gel in the treated lanes

to detect DNA methylation in both rice and petunia treated with 5-azacytidine, this technique was extended to detect methylation in spinach and longan.

In spinach, the three distinct treatment effects (5azacytidine, $\mathrm{KClO}_{3}$ and low temperature) each showed phenotypic differences the most significant of which was a reduced time to flowering of over a week for all three treatments. To test whether these treatments had a methylation dependent effect as was seen in rice and petunia, each treatment was amplified using the two arbitrary primers OPW09 and OPL04 and digested with the enzyme MspI. As was found in rice and petunia, each of the three treatment effects showed polymorphic bands indicating that there was a methylation effect. With the potassium chlorate treatment, a total of 3 distinct agarose bands were found, after treatment with 5-azacytidine a total of 6 bands were found and lastly with the low temperature treatment a single band polymorphism was found. Since a large number of polymorphic bands were found with enzyme $M s p$ I showing the methylation dependence no further samples were run with enzyme HpaII in spinach.

The last treatment effect tested whether the use of potassium chlorate in longan had a methylation dependent effect as is seen in many other plants including rice, petunia and spinach or whether a different set of biochemical signals are at work in longan. An initial testing of longan with the potassium chlorate treatment effect using the two arbitrary primers OPW09 and OPL04 and the two enzyme MspI and $\mathrm{H} p a \mathrm{II}$ found no polymorphic bands in the agarose gel electrophoresis. Four agarose gel images showing this lack of polymorphism are shown in Fig. 3. Due to the lack of polymorphic bands, an additional three arbitrary primers (OPC09, OPH06 and OPL15) were tested with longan, but even with the additional primers not a single methylation dependent band difference was found. Using these five arbitrary primers, two enzymes and samples takes at four different timepoints, not a single polymorphic band was found suggesting that the difference in flowering in longan is not a methylation dependent process.

The action of vernalization in some tropical plants is known to be a methylation mediated response to environmental stressors and is thought to provide an external signal for plants to bear fruit at an optimal time. One downside of this temperature dependence for floral induction though is that the availability of these types of tropical fruits is limited to the specific temporal window which exactly fits the requirements of the plant to bear fruit. These specific temperature requirements often also limit the geographic range in which such tropical plants can bear fruit. By understanding the mechanisms and ultimately the biochemical pathways involved in the vernalization response, it may be possible to develop external signals (such as the potassium chlorate treatment in longan) to induce flowering whenever or wherever desired. Towards this end we have applied the HAT-RAPD DNA amplification methodology to test for the presence of methylation dependent floral induction in jasmine rice (Oryza sativa indica KDML 105), petunia, spinach and longan by inducing with $\mathrm{KClO}_{3}$, 5azacytidine and low temperature $\left(10^{\circ} \mathrm{C}\right)$ treatments. For these four species, we found that rice, petunia showed methylation dependent changes consistent with previously reported studies which provided a positive control to test the methodology. For spinach, methylation dependent DNA changes were also found to be correlated with the vernalization response, potassium chlorate treatment and 5-azacytidine suggesting that similar biochemical responses may be involved in the flowering response, whereas longan showed no methylation response.

Due to the recent success of inducing longan offseason, the possibility of inducing other tropical plants in a similar fashion has begun to look more promising, 


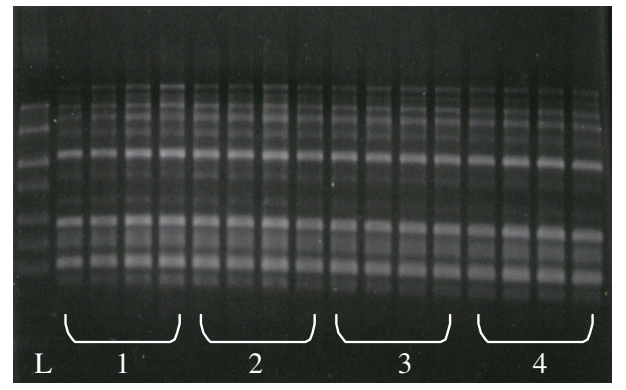

(a) OPW09 HpaII

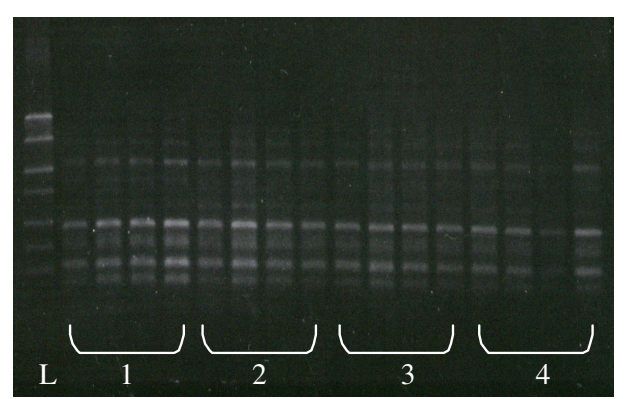

(b) OPW09 MspI

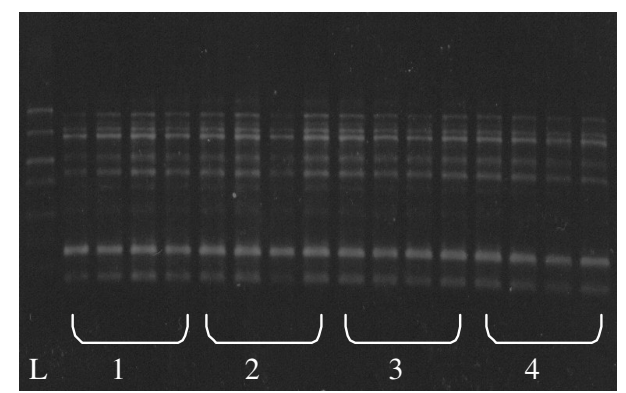

(c) OPL04 HpaII

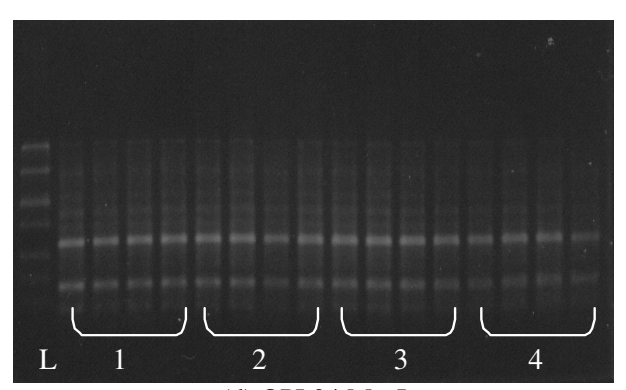

(d) OPL04 MspI

Fig. 3: HAT-RAPD agarose gel images for longan genomic DNA amplified with arbitrary primers OPL04 and OPW09 and digested with enzymes HpaII or MspI. Lane groups 1-3 each contain four samples from a single tree treated with potassium chlorate at 20,30,40 and 60 days. Lane group 4 contains four samples from leaves of a longan tree without treatment and the same timepoints. The standard ladder is labeled $\mathrm{L}$ but without an understanding of the biochemical mechanisms involved in this response, such an undertaking is essentially a process of shooting into the dark. In this work, we have shown that at least for longan the floral induction response in response to potassium chlorate is not a methylation associated process.

\section{ACKNOWLEDGEMENTS}

This research was conducted using funding from the following sources: TRF (Thailand Research Fund), NRCT (National Research Council of Thailand), and Mark Halsey the Dean of the Science Division of Bard College. We also wish to thank Dr. Nopmanee Topoonyanoot for her laboratory support.

\section{REFERENCES}

1. Burn, J.E., D.J. Bagnall, J.D. Metzger, E.S. Dennis and W.J. Peacock, 1993. DNA methylation, vernalization and the initiation of flowering. Proc. Natl. Acad. Sci. USA, 90: 287-291.

2. Demeulemeester, M.A.C., N. Van-Stallen and M.P. De Proft, 1999. Degree of DNA methylation in chicory (Cichorium intybus L.): Influrence of plant age and vernalization. Plant Sci., 142: 101-108.

3. Sano, H., I. Kamada, S. Youssefian, M. Katsumi and H.A. Wabiko, 1990. Single treatment of rice seedlings with 5-azacytidine induces heritable dwarfism and undermethylation of genomic DNA. Mol. Gen. Genet., 220: 441-447.

4. Cherdshewasart, W., S. Samransuk, B. Ngarmpanya, J. Narangajawana and $M$. Vajraphaya, 1998. Induction of dwarf and high tillering number in indica rice by 5-azacytidine. In: Proceedings of the 2nd Thai-French Symposium on Plant Molecular Biology, Laigretss, F. and Renaudin, J., eds. (INRA) Bordeaux, France, pp: 36-46.

5. Prakash, A.P. and P.P. Kumar, 1997. Inhibition of Shoot Induction by 5-azacytidine and 5-aza-2'deoxycytidine in Petunia Involves DNA Hypomethylation. Plant Cell Rep., 16: 719-724.

6. Gruenbaum, Y., H. Cedar and A. Razin, 1982. A substrate and sequence specificity of a eukaryotic DNA Methylase. Nature, 295: 620-622.

7. Manochai, P., P. Sruamsiri, W. Wiriya-alongkorn, D. Naphrom, M. Hegele and F. Bangerth, 2005. Year around off-season flower induction in longan (Dimocarpus longan Lour) trees by $\mathrm{KClO}_{3}$ applications: potentials and problems, Sci. Horticult., 104: 379-390. 
8. Menzel, C.M. and G.K. Waite, 2005. Litchi and Longan-Botany Production and Uses. CABI Publishing, UK, pp: 26.

9. Cutler, R.W., R. Chundet, T. Handa and S. Anuntalabhochai, 2006. Development of sequence characterized DNA markers linked to a temperature dependence for flower induction in lychee (Litchi chinensis Sonn.) cultivars. Sci. Horticult., 107: 264-270.

10. Cutler, R.W., S. Sitthiphrom, J. Marha and S. Anuntalabhochai, 2007. Development of sequence characterized DNA markers linked to a temperature insensitivity for fruit production in longan (Dimocarpus longan Lour.) cultivars, J. Agron. Crop Sci., 193: 74-78.

11. Topoonyanont, N., P. Nuamjaroen and S. Anuntalabhocahi, 2000. Flower induction in spinach (Spinacia oleracea L.) by potassium chlorate and 5-azacytidine, In: Proceedings of the 26th Conference of Science and Technology of Thailand Queen Sirikit National Conventional Center, Bangkok, Thailand, pp: 18-20.

12. Topoonyanont, N., P. Nuamjaroen, P. Hongwithakorn, P. Manochai, S. Chongsang and S. Anuntalabhocahi, 2001. Effect of potassium chlorate on floral induction of cold-requirement vegetable crops in vitro. In: Proceedings of the 3rd Maejo University Annual Conference, 26-27 July, pp: 364-377.
13. Anuntalabhochai, S., R. Chundet, J. Chiangda and P. Apavatjrut, 2000. Genetic Diversity within Lychee (Litchi chinensis Sonn.) Based on RAPD Analysis. In: International Symposium on Tropical and Subtropical Fruits, Symposium Booklet, Cairns, Australia 45.

14. McClelland, M., 1983. The frequency and distribution of methylatable DNA sequences in leguminous plant protein coding genes. J. Mol. Evol., 19: 346-354.

15. Doyle, J.J. and J.L. Doyle, 1990. A rapid DNA isolation procedure for small quantities of fresh leaf tissue. Phytochem. Bull., 19:11-15.

16. Finnegan, E.J., R.K. Genger, W.J. Peacock and E.S. Dennis, 1998. Dna Methylation in plants. Annu. Rev. Plant Physiol. Plant Mol. Biol., 49: 223-247. 